\title{
The optimisation of a water distribution system using Bentley WaterGEMS software
}

\author{
Karolina Świtnicka ${ }^{1, *}$, Paweł Suchorab ${ }^{1}$, and Beata Kowalska ${ }^{1}$ \\ ${ }^{1}$ Lublin University of Technology, Faculty of Environmental Engineering, Nadbystrzycka 40 B, 20-618 Lublin, Poland
}

\begin{abstract}
The proper maintenance of water distribution systems (WDSs) requires from operators multiple actions in order to ensure optimal functioning. Usually, all requirements should be adjusted simultaneously. Therefore, the decision-making process is often supported by multi-criteria optimisation methods. Significant improvements of exploitation conditions of WDSs functioning can be achieved by connecting small water supply networks into group systems. Among many potential tools supporting advanced maintenance and management of WDSs, significant improvements have tools that can find the optimal solution by the implemented mechanism of metaheuristic methods, such as the genetic algorithm. In this paper, an exemplary WDS functioning optimisation is presented, in relevance to a group water supply system. The action range of optimised parameters included: maximisation of water flow velocity, regulation of pressure head, minimisation of water retention time in a network (water age) and minimisation of pump energy consumption. All simulations were performed in Bentley WaterGEMS software.
\end{abstract}

\section{Introduction}

The main function of water distribution systems (WDSs) is to deliver water to consumers. That goal remains overriding to other purposes of the company, but nowadays water operators endeavour to achieve that goal in the most efficient way. To ensure optimal functioning of WDS, it is required from operators to take multiple actions, sometimes simultaneously. Therefore, the decision-making processes are often supported by multicriteria optimisation methods. Significant improvements of exploitation conditions of WDSs functioning can be achieved by connecting small water supply networks into group systems. Among many potential tools supporting advanced maintenance and management of WDSs, a significant note is those tools that can find the optimal solution automatically, by the implemented mechanism of metaheuristic methods, such as the genetic algorithm [1].

In this paper, an exemplary WDS functioning optimisation is presented, in reference to a group water supply system. On the territory of the commune, 6 different WDSs are operated by one water company. In the near future, it is planned to create one group water system, supplying water to all inhabitants of the commune (over 20000 people). As this process is of great complexity, it is divided into several steps, the first of all being the connection of urban WDS with the biggest rural WDS. In accordance to water company expectations and requirements, the aim of this paper was to define the required actions from the WDS operators in order to connect and optimise selected water distribution networks. The analysis of optimal connection and functioning solutions was based on computer simulations performed in Bentley WaterGEMS software.

\section{Methodology}

Analysed WDSs are located in the Lublin Region and supply water to two neighbouring settlement units: one of an urban (settlement A - approx. 10000 consumers) and one of a rural character (settlement B - approx. 400 consumers). Branched-looped water distribution networks are made both of traditional materials (steel, cost iron, asbestos-cement), as well as from plastic pipes (PVC, $\mathrm{PE}$ ). The total length of water network A is approx. $54 \mathrm{~km}$ and network B - approx. $66 \mathrm{~km}$. Distribution pipe diameters in both systems varies from DN80 up to DN225. Presently, two analysed WDSs are operated individually. The geometrical structure of analysed WDSs with diameter differentiation and marked areas of settlements A and B is presented in figure 1. The territory of analysed WDSs varies significantly in geographical elevation $(129.70 \div 181.05 \mathrm{~m}$ above sea level).

The required pressure head is provided by 4 pumps in 2 pump stations in each WDS (A1, A2 in WDS A and B1, $\mathrm{B} 2$ in WDS B). The functioning of all pumps stations is supervised by water company operators through on-line monitoring system. In each of the analysed systems, two specific moments in 24-hours of operation can be defined. The hour of maximum water demands (A - 19:00, B $11: 00)$ and the hour of the minimum water demands (A 2:00, B - 5:00).

\footnotetext{
*Corresponding author: karolina2393@wp.pl
} 


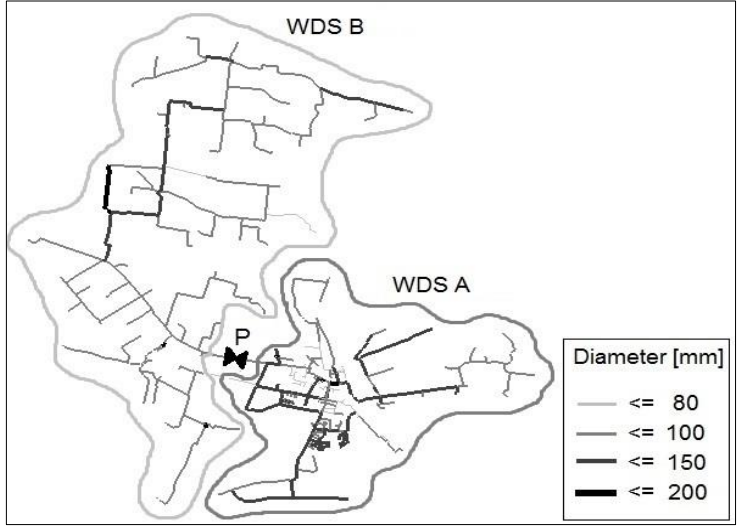

Fig. 1. Geometrical structure of analysed WDSs.

The analysis of optimal connection and operating solutions of analysed systems was based on computer simulations in Bentley WaterGEMS software. It is a widely applied [2-4] hydraulic modelling software for water distribution systems with advanced interoperability. Among many modules, WaterGEMS can be used to support the design process of new distribution systems, assess fire flow capacity, develop network flushing plans, identify water losses, manage and minimize energy use and prioritize pipe renewal [5].

Numerical model of analysed WDSs has a basic character - water supply networks were composed only of main distribution pipes, without households' connections. The model is composed of 548 junctions, 565 pipes, 2 pressure reduction valves (PRVs), 4 pumps and 3 water sources - reservoirs. Before the analysis, the model was validated and calibrated. The basis of calibration was the results of a pressure and flow measuring campaign. The percentage of measurement nodes fulfilled the required minimal amount of measurement points ( $2 \%$ of all nodes) for the designing and operation purposes [6]. The fitting of the model results to the real network conditions was estimated as satisfactory (determination coefficient $R^{2}$ of measured and simulated values equalled $97.7 \%$ ). The total duration of the extended period simulation (EPS) time was 480 hours (20 days), with computation hydraulic time step 1 hour.

The process of connecting and optimising A and B WDSs was focused on fulfilling several requirements and expectations addressed by the water company, which the most important are as follows:

- minimisation of energy consumption for pumping and reducing energy costs,

- improvement of hydraulic operating conditions of WDS (increasing in-water flow velocity and prevention to secondary water contamination by decreasing of water retention time (water age)) by connecting network branches into looped structures,

- the assurance of proper water pressure head acquired by pump parameters modification and fittings installation.

Taking into consideration all expected results, the process of connecting and optimising analysed WDSs was divided into three succeeding steps:
1. Simulating the connection process by systems linked with additional pipes, simultaneously with pump parameters adjustment.

2. Optimisation of WDS with the use of the Darwin Scheduler module with implemented genetic algorithm setting pump parameters in reference to expected pressure head values in nodes and required water flow velocity in pipes.

3. Additional optimisation - localizing new PRVs, new pipe connections and manual modification of pumps speed variable patterns.

The connection pipe $(\mathrm{P})$ between $\mathrm{A}$ and $\mathrm{B}$ networks (length $1300 \mathrm{~m}$, diameter DN110, material PE) is marked in figure 1. That connection pipe is already linking networks, but is not yet operated (closed gate valves at the beginning and at the end of the pipe). Together with the network connecting, the pumps parameters were expected to be adjusted accordingly. Additionally, after the WDSs connection, it was required to specify the hour of minimal and maximum water demands common for the whole system. In order to evaluate the effects of a systems' connection, it was necessary to examine basic hydraulic operating conditions: pressure head in nodes in the hour of minimal and maximal water demands, water flow velocity in pipes in the hour of maximal demands and water age in the network at the time step of the simulation. The results of hydraulic functioning conditions were used to further indicate the purposes of the systems' optimisation.

Darwin Scheduler module, based on the genetic algorithm, allows automatic optimisation of pumps operation by variable pump speed modifications, in order to fulfil requested hydraulic parameters. As a result, the lowering of the energy consumption is expected, and therefore the decreasing of pumping costs. In the analysed case, the automatized optimisation module was used for all 4 pumps which originally worked with $100 \%$ efficiency. Three general restrictive conditions for the whole WDS were assumed in the optimisation process: the minimum pressure head in water system $\left(30 \mathrm{~m} \mathrm{H}_{2} \mathrm{O}\right.$ in the urban area and $20 \mathrm{~m} \mathrm{H}_{2} \mathrm{O}$ in rural area), the maximum pressure head $\left(60 \mathrm{~m} \mathrm{H}_{2} \mathrm{O}\right)$ and the maximum acceptable flow velocity for distribution pipes $(3 \mathrm{~m} / \mathrm{s})$. The selected objective type of Darwin Scheduler module was to Minimize Energy Cost of pumping with simultaneous achieving of requested hydraulic parameters. The parameters of pump stations to optimize, such as decision type, speed properties and time specifications, are presented in the screen capture of a selected window of Darwin Scheduler module in figure 2. In order to calculate pumping costs, two industrial Energy Pricing tariff patterns were used: a) daily constant energy price $(0.25$ $\mathrm{PLN} / \mathrm{kWh}$ ) and b) price tariff with night price reduction (0.29 PLN/kWh during 6:00 $\div 21: 00$, and 0.18 PLN/kWh in $21: 00 \div 6: 00$ ). Additionally, during the optimisation process, the $\mathrm{CO}_{2}$ emission was calculated in reference to energy use (the assumed $\mathrm{CO}_{2}$ emission coefficient equalled $0.83 \mathrm{~kg} / \mathrm{kWh}$ [7]). 


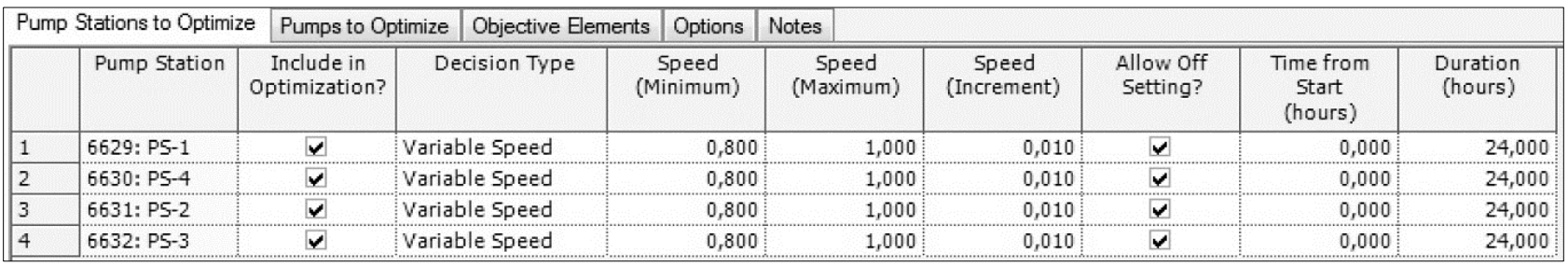

Fig. 2. Screen capture of a selected window "Pump stations to optimize" from Darwin Scheduler module.

Due to the fact that Darwin Scheduler module does not include the automatized possibility of new fitting installations or new pipe connections, it was decided to perform additional optimisation actions. The base for the additional optimisation was the WDS connection scenario from the optimisation module. The aim of the additional optimisation was to reduce pressure in the head in selected zones of increased pressure and limit the water age in the network. It was assumed by localizing 5 new PRVs and by designing 2 new pipe connections. Moreover, the pumps speed variable pattern of pump B1 was modified to further minimize pumping energy costs.

\section{Results}

In accordance to the presented methodology, the connection and optimisation process was divided into three steps. Connecting two separate WDSs into one system by linking two networks with a connection pipe resulted in dysregulation of proper system functioning. According to the simulation performed in Bentley WaterGEMS, in night hours $(0: 00 \div 3: 00)$ the system operation was failing because several pumps could not deliver required water flow or pressure head. Therefore, it was necessary to manually modify pump properties: increase (pumps A1, A2) and decrease (pump B2) in maximal head. After several modifications, the simulated system was balanced and characterized with attributes presented in table 1 (parameters after step 1). After analysis of the WDS hydraulic parameters, several aspects of connection require improvement: an increase in minimum pressure head in the urban area, the reduction of maximum pressure head in the urban area, increasing flow velocity in pipes and lowering of water age. These goals were applied as the base for the automated optimisation.

The Darwin Scheduler module was used to automatically optimise the WDS in order to minimize the energy costs of pumping. The applied module modified pump speed variable patterns to adjust pump operation in reference to requested hydraulic restrictions. The main goal of the application of Minimize Energy Cost objective type of Darwin Scheduler resulted in a $1.4 \%$ reduction of daily pump energy consumption. It also resulted in smaller $\mathrm{CO}_{2}$ emissions (reduction from $91.7 \mathrm{~kg}$ to 90.44 $\mathrm{kg}$ per day).Comparing hydraulic operation conditions of WDS before and after the optimisation in WaterGEMS, it is clearly visible that some of the requested parameters are achieved. The minimum pressure head in the urban area is set as the expected value $\left(30 \mathrm{~m} \mathrm{H}_{2} \mathrm{O}\right)$. However, other pressure head values did not improve significantly (the decrease of maximum pressure head in urban area only by
$0.5 \mathrm{~m} \mathrm{H}_{2} \mathrm{O}$ ). Additionally water flow velocity and water age did not improve to an acceptable level. Detailed characteristics of the WDS after the optimisation in Darwin Scheduler module are given in table 1 (step 2).

Table 1. Results of WDS optimisation (step: 1 - connection, 2 - automatized optimization, 3 - additional optimisation).

\begin{tabular}{|c|c|c|c|}
\hline Parameter & $\begin{array}{l}\text { After } \\
\text { step } 1\end{array}$ & $\begin{array}{l}\text { After } \\
\text { step } 2\end{array}$ & $\begin{array}{l}\text { After } \\
\text { step } 3\end{array}$ \\
\hline $\begin{array}{l}\text { Maximum pressure head } \\
\left(\mathrm{m} \mathrm{H}_{2} \mathrm{O}\right) \text { - urban area }\end{array}$ & 69.70 & 69.20 & 60.00 \\
\hline $\begin{array}{l}\text { Minimum pressure head } \\
\left(\mathrm{m} \mathrm{H}_{2} \mathrm{O}\right) \text { - urban area }\end{array}$ & 28.39 & 30.00 & 30.00 \\
\hline $\begin{array}{l}\text { Maximum pressure head } \\
\left(\mathrm{m} \mathrm{H}_{2} \mathrm{O}\right) \text { - rural area }\end{array}$ & 54.19 & 54.19 & 50.10 \\
\hline $\begin{array}{l}\text { Minimum pressure head } \\
\left(\mathrm{m} \mathrm{H}_{2} \mathrm{O}\right) \text { - rural area }\end{array}$ & 20.17 & 20.17 & 21.77 \\
\hline $\begin{array}{l}\text { Maximum flow velocity in } \\
\text { pipe } X(\mathrm{~m} / \mathrm{s})\end{array}$ & 0.00 & 0.00 & 0.13 \\
\hline $\begin{array}{l}\text { Water age in node Yin } 480 \\
\text { hour of simulation(hours) }\end{array}$ & 287.14 & 287.14 & 8.47 \\
\hline $\begin{array}{c}\text { Daily pump energy } \\
\text { consumption ( } \% \text { to the } \\
\text { original one) }\end{array}$ & 100 & 98.6 & 97.5 \\
\hline $\begin{array}{c}\text { Daily } \mathrm{CO}_{2} \text { emission } \\
(\mathrm{kg} / \mathrm{d})\end{array}$ & 91.70 & 90.44 & 89.41 \\
\hline
\end{tabular}

As the results of the automatic optimisation were not fully satisfactory, additional optimisation was focused on for further improvement of hydraulic conditions. In order to eliminate zones of higher-pressure head, 5 new PRVs were designed. The increase of water flow velocity in pipes was proposed by combining network branches into loops by 2 new connection pipes. The localisation of PRVs and connection pipes is presented in figure 3 . Additionally, variable speed patterns of pump B1 was modified manually in order to obtain more satisfactory effects of energy consumption reduction. The modified variable speed pump B1 pattern is presented in figure 4 .

Detailed effects of the additional optimisation are presented in table 1 (step 3). The installation of new PRVs resulted in proper water pressure head range in the system. Zones of increased pressure were eliminated, and the maximum pressure head value in the urban part of the water system equalled $60 \mathrm{~m} \mathrm{H}_{2} \mathrm{O}$. Moreover, the pressure head in the rural area was lowered, which can positively influence the maintaining process of the WDS. 


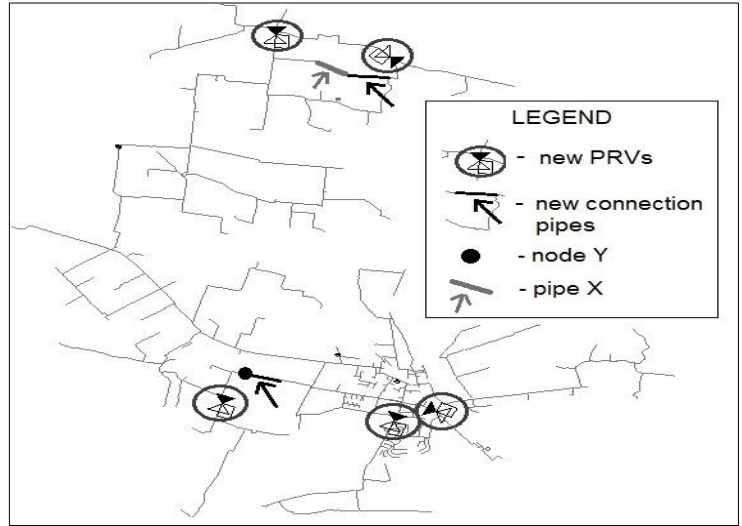

Fig. 3. Geometrical structure of the WDS with marked locations of new PRVs, new connection pipes and exemplary reference pipe and node.

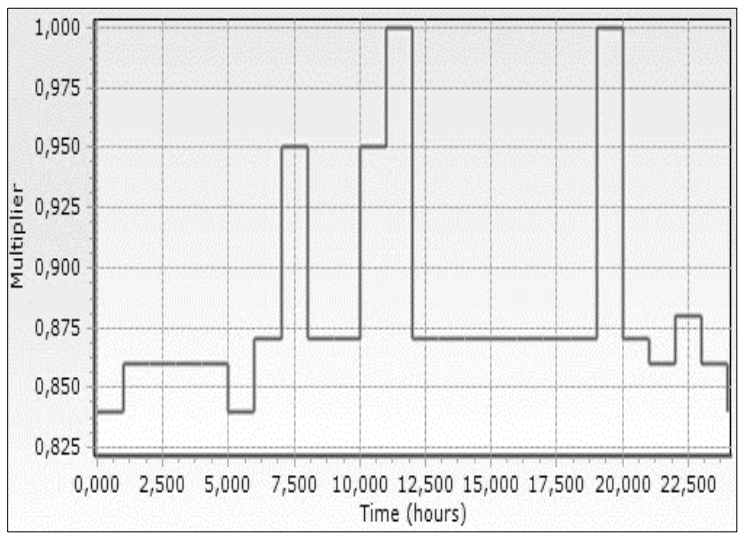

Fig. 4. Variable speed pattern for exemplary pump (B1) after modifications (other pumps are optimized in a similar way).

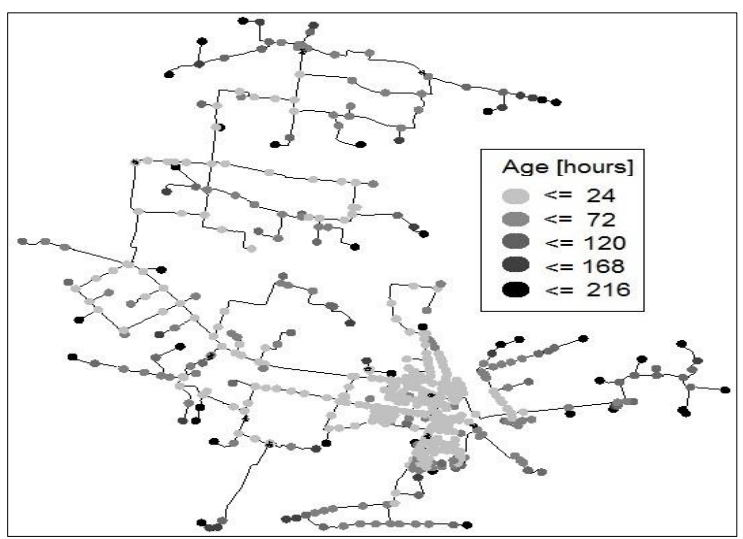

Fig. 5. Water age in the analysed WDS after additional optimisation in 480 hour of simulation.

New connections of branches into loops reflected in an increase of the flow velocity in these parts of the system. Locally, the flow velocity improved from $0.0 \mathrm{~m} / \mathrm{s}$ up to $0.13 \mathrm{~m} / \mathrm{s}$. However, on the whole, WDS water flow velocities are generally still below the minimum recommended level $(0.5 \mathrm{~m} / \mathrm{s})$. Additionally, new connections resulted in locally greater water age lowering (in reference node from 287.14 hour to 8.47 hour), but general water age in the system did not decrease significantly. The water age in nodes in 480 hours of the simulation is presented in figure 5. However, in the majority of nodes water flows to customers in less than 24 hours, which is shorter than permissible water age in a distribution network (1.3 day) [8]. By additional optimisation not only was an improvement of hydraulic conditions achieved, further energy costs were minimised (to the level of $97.5 \%$ of the original consumed energy).

\section{Conclusion}

The main result of this analysis is the action scenario for the water company, in which several steps are defined in order to connect and optimise maintained water distribution systems. In accordance to the obtained results, the application of proposed modifications in pump properties and the installation of new fittings would reflect in energy consumption minimisation and an improvement in hydraulic water conditions.

The performed analysis confirmed that the connecting of different water distribution systems into one group and optimising its operation is a process of great complexity. Therefore, it is always highly recommended to predict further actions in modelling software before its realization. The applied Bentley WaterGEMS software, with the genetic algorithm modules implemented, proved to be a very useful and universal tool, which can be used to support the decisive-making process of maintenance planning.

\section{References}

1. S. M. S.Abkenar, S. D. Stanley, C. J. Miller, D. V. Chase, S. P. McElmurry, SUSCOM 8 (2015)

2. J. Stańczyk, E. Burszta-Adamiak, D. Poor, GWiTS, 5 (2017) DOI: 10.15199/17.2017.5.4

3. C. Xiao, B. Li, G. He, J. Sun, J. Ping, R. Wang, Procedia Eng. 89 (2014) DOI: 10.1016/j.proeng.2014.11.203

4. P. Sage, Procedia Eng. 70 (2014) DOI: 10.1016/.j.proeng.2014.02.160

5. Bentley WaterGEMS Product Data Sheet www.bentley.com/en/resources/watergems [access 8.10.2017]

6. AWWA Engineering Computer Applications Committee, Calibration Guidelines for water distribution system modelling (1999)

7. KOBIZE, Wskaźniki emisyjności $\mathrm{CO}_{2}$ dla energii elektrycznej (2014) (in Polish)

8. U.S. EPA, Effects of Water Age on Distribution System Water Quality (2002) 